\title{
Rancang Bangun Sistem Rekomendasi Pariwisata Mobile Advertising Menggunakan Metode Hybrid Filtering Sebagai Pemberdayaan Masyarakat Usaha Kecil Menengah (UKM) di Pulau Ternate
}

\author{
Assaf Arief \\ Program Studi Teknik Informatika \\ Fakultas Teknik, Universitas Khairun \\ E-mail : assafarief83@gmail.com
}

\begin{abstract}
Abstrak - Isu Smart Taourism (Wisata Pintar) memiliki topik populer dalam beberapa waktu terakhir, hasil ini dalam peningkatan jumlah prototipe pariwisata aplikasi desktop berbasis web dan berbasis mobile. Penelitian ini berfokus untuk meningkatkan kualitas layanan pariwisata pintar dengan membangun sebuah aplikasi sistem rekomendasi otomatis yang dapat berjalan pada perangkat mobile seperti komputer tablet, PDA (Personal Digital Assistance), smartphone, iPod, dll. Sistem rekomendasi pariwisata yang umumnya meminta saran dari petugas untuk membantu memilih tempat wisata yang akan dikunjungi, yang masih dianggap sebagai opini subjektif. Hal ini menjadi kurang tepat dalam penggunaan teknologi informasi, perilaku, minat, selera, dan rating untuk disampaikan kepada wisatawan lainnya dengan preferensi yang sama, yang itu adalah dasar untuk memberikan sistem rekomendasi konten wisata.

Berdasarkan latar belakang di atas, beberapa permasalahan mendasar yang diangkat; Pertama, bagaimana merancang dan implementasi sistem rekomendasi mobile advertising untuk pariwisata global, yang membutuhkan saran/rekomendasi dalam memutuskan menarik terkait sesuai dengan kepentingan dan preferensi mereka?. Kedua, bagaimana mendesain sebuah aplikasi dari sistem mobile advertising menggunakan sistem penyaringan hybrid dengan metode Collaborative Filtering (CF) dan metode berbasis content (CBF) dan juga menggunakan layanan Location Based Services (LBS) pendekatan sehingga untuk merekomendasikan atraksi / tempat sesuai dengan kondisi saat ini dan posisi saat ini ?. Ketiga, bagaimana teknologi ini dirancang untuk membantu memberikan solusi alternatif untuk pariwisata daerah promosi sehingga meningkatkan kemandirian ekonomi masyarakat perusahaan pariwisata kecil dan menengah di Pulau Ternate.
\end{abstract}

Kata Kunci: Mobile Advertising, Collaborative Filtering (CF), Hybrid filtering, Usaha Kecil dan Menengah, Ternate.

\section{Pendahuluan}

Dewasa ini, perkembangan teknologi perangkat mobile sangatlah pesat, mulai dari telepon seluler, komputer jinjing, smartphone, iPad, PC Tablet, Gadget dan lain sebagainya. Perangkat-perangkat ini menggantikan perangkat-perangkat pendahulunya seperti desktop komputer dan telepon rumah yang menggunakan kabel. Karena kepraktisannya untuk dapat dibawa ke mana-mana, maka saat ini banyak orang yang beralih ke perangkat mobile. Penggunaan aplikasi internet di bidang pariwisata telah terimplementasi melalui beberapa sistem diantaranya adalah e-tourism, tourism virtual reality mapping, tourism reservation system, location-based tourism services, mobile advertising dan tourism recommender system. Dari berbagai sistem aplikasi tersebut, sistem rekomendasi pariwisata mempunyai peran yang penting karena mampu memberikan penyaringan dari informasi yang sangat bayak (overload) di dunia maya untuk memberikan saran/rekomendasi pilihan objek wisata sesuai dengan minat dan kebutuhan calon wisatawan.

Visi pembangunan kepariwisataan nasional menegaskan bahwa pembangunan kepariwisataan merupakan bagian penting dari proses pembangunan nasional karena mempunyai peranan penting dalam peningkatan kesejahteraan rakyat. Pariwisata juga berperan dalam upaya meningkatkan jati diri bangsa dan mendorong kesadaran dan kebanggaan masyarakat terhadap kekayaaan alam dan budaya bangsa[1]. Salah satu provinsi termuda di Indonesia yang menjadi aset pariwisata nasional adalah propinsi Maluku Utara. Pariwisata di Maluku Utara mempunyai potensi yang besar untuk dikembangkan diantaranya potensi Pariwisata Alam dan Kuliner (Makanan Khas Daerah).

Daerah pulau Ternate yang terletak di kawasan timur Indonesia di propinsi Maluku Utara, memiliki potensi pariwisata yang besar berupa keindahan alam dan budaya yang masih asli dan belum tercemar lingkungannya sangat membutuhkan pengelolaan dan pemberdayaan yang dapat menjadi keistimewaan tersendiri bagi pembangunan di daerah tersebut. Objek wisata pantai seperti pantai sumaladaha, pantai kastela, pantai swering dll, belum dikelola secara optimal baik dari segi promosi wisata maupun pengelolaan makanan khas daerah (kuliner) oleh masyarakat usaha kecil menengah di daerah tersebut. Olehnya itu butuh teknologi terapan yang berdayaguna untuk membantu memberdayakan masyarakat usaha kecil menengah di bidang pariwisata pulau Ternate tersebut agar lebih mampu mempromosikan usaha pariwisatanya agar lebih mandiri secara ekonomi. 
Trend penggunaan perangkat mobile oleh wisatawan global inilah yang menjadi perhatian dalam mempromosikan objek-objek wisata daerah di pulau Ternate. Selain itu perkembangan jumlah informasi yang begitu banyak di dunia maya menyebabkan sulitnya menemukan informasi tepat yang sesuai dengan selera/preferensi dan minat calon wisatawan. Dalam mengatasi hal tersebut, perancangan otomasi sistem rekomendasi pariwisata yang menawarkan dan menyarankan beberapa objek wisata tertentu kepada calon wisatawan global dengan menggunakan pendekatan hybrid filtering yaitu penyaringan informasi dengan metode gabungan berdasarkan penyaringan secara kolaboratif (collaborative filtering) dan penyaringan secara konten (content based filtering) serta menggunakan layanan berbasis lokasi yang merekomendasikan objek wisata tertentu berdasarkan jarak terdekat dari tempat pengguna. Aplikasi mobile pariwisata yang dirancang dengan menggunakan metode hybrid filtering diharapkan dapat meningkatkan mutu item dari objek wisata yang diwarkan sistem dapat sesuai dengan kebutuhan dan preferensi pengguna. Selain itu, sistem ini juga dikembangkan dengan menggunakan pendekatan layanan berbasis lokasi untuk menawarkan item dari objek wisata yang terdekat dari lokasi pengguna saat itu. Layanan berbasis lokasi tersebut juga dikembangkan dengan menggunakan aplikasi peta pariwisata pulau Ternate untuk memberikan fitur layanan geospasial kepada pengguna untuk kemudahan dalam penggunaan aplikasi ini (user friendly).

\section{Tinjauan Pustaka}

\section{A. Sistem Rekomendasi}

Sistem Rekomendasi atau Recommender System (terkadang mengartikan "sistem" dengan sinonim seperti "platform" atau "mesin") adalah sub bagian dari sistem penyaringan informasi yang mencoba untuk memprediksi rating atau preferensi yang pengguna berikan kepada suatu item/objek (seperti musik, buku atau film) atau elemen sosial (misalnya orang atau kelompok) yang belum dipertimbangkan oleh pengguna, menggunakan pemodelan yang dibangun dari karakteristik item (pendekatan berbasis konten) atau lingkungan sosial pengguna (pendekatan berdasarkan penyaringan kolaboratif [2]. Sistem Rekomendasi (SR) merupakan alat pencarian informasi yang baru-baru ini di usulkan untuk mengatasi masalah overload informasi, masalah yang bisanya dihadapi oleh pengguna aplikasi web yaitu memiliki terlalu banyak informasi untuk membuat keputusan atau kurangnya informasi tentang suatu topik/item. Misalnya, pengguna yang sedang melihat situs $e$ commerce (contohnya, amazon.com) untuk mencari buku yang ingin dibelinya atau konten situs web yang lainnya yang menawarkan produk/item yang sama pengguna dalam hal ini bisa kewalahan oleh banyaknya jumlah halaman yang relevan dari semua situs halaman web yang dibuka. Maka, dalam rangka mengatasi hal inilah SR ini di usulkan [2].

Salah satu bidang penelitian yang sedang berkembang di bidang sistem rekomendasi adalah mobile recommender system. Inovasi dari aplikasi mobile recommender system untuk panduan wisata dikenal dengan mobile tourism guide yaitu aplikasi sistem panduan pariwisata yang berjalan pada perangkat mobile sehingga memungkinkan calon wisatawan untuk mendapatkan rekomendasi tempat wisata yang sesuai dengan preferensi pengguna baik tempat wisata yang sudah pernah dikunjungi maupun belum pernah dikunjungi dengan memanfaatkan perangkat mobile pribadinya. Sistem juga memungkinkan pengguna untuk menilai atau mengulas suatu objek wisata yang pernah dikunjungi dan dapat dibagikan dengan pengguna lain yang memiliki kesamaan preferensi dengan dirinya [2].

Tugas inti dari komputasi Sistem Rekomendasi (SR) adalah memprediksi dari evaluasi subjektif pengguna yang akan memberikan penilaian terhadap sebuah item/produk. Prediksi ini dihitung dengan menggunakan sejumlah model prediktif yang memiliki karakteristik umum yaitu mereka mengeksploitasi evaluasi dan penilaian (rating) yang diberikan oleh para pengguna untuk item/barang yang sebelumnya dilihat atau dibeli. Berdasarkan teknik prediksi tertentu yang sedang digunakan, sistem rekomendasi telah diklasifikasikan ke dalam empat kategori utama yaitu sistem berbasis kolaboratif (collaborative filtering), sistem berbasis konten (content-based filtering), sistem berbasis pengetahuan (knowledge-based) dan sistem hybrid (gabungan) [5].

Secara sederhana prinsip kerja sistem berbasis kolaboratif (collaborative filtering) yaitu menghitung korelasi antara pengguna, mereka memprediksi peringkat item/produk untuk pengguna saat ini didasarkan pada peringkat yang diberikan oleh pengguna lain, yang memiliki preferensi yang sangat berkorelasi dengan pengguna saat ini [5]. Pendekatan baru dan lebih canggih yang didasarkan pada teknik dekomposisi matriks, mereka mencoba untuk mendekati matriks user-item, yaitu matriks dua dimensi dengan entri pada posisi $(i, j)$ sama dengan peringkat (rating) yang diberikan oleh pengguna ke-i dan item ke-j, sebagai produk dari dua matriks yang lebih kecil[6]. Sebagian besar dimasukan dalam matriks asli sebenarnya tidak diketahui dan dengan faktorisasi ini prediksi dihitung untuk semua nilai hilang.

Sistem berbasis konten (content-based filtering) hanya menggunakan preferensi pengguna saat itu, sistem memprediksi peringkat untuk item yang belum pernah dilihat berdasarkan pada berapa banyak deskripsi konten yaitu item yang diberi rating tinggi di masa lalu[5]. Pendekatan ini didasarkan pada teknik pencarian informasi karena deskripsi item biasanya berupa teks, dan vektor (fitur based) representasi diturunkan dengan mengidentifikasi kata kunci yang paling relevan yang muncul dalam teks.

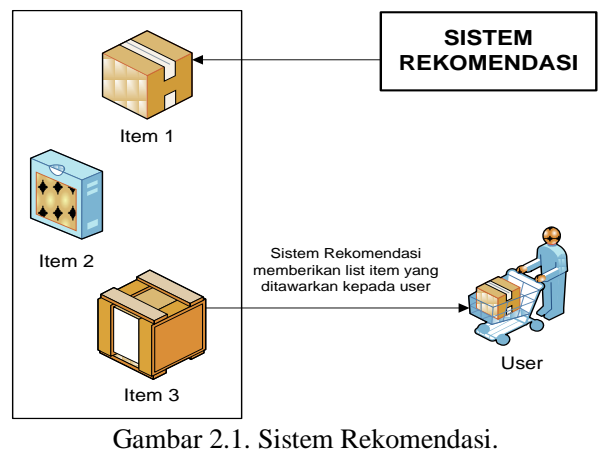

Gambar 2.1. Sistem Rekomendasi. 


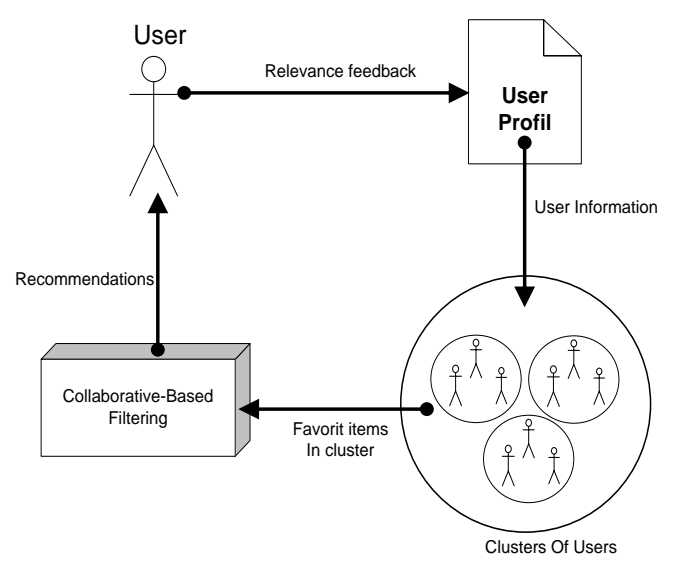

Gambar 2.2. Arsitektur Collaborative Filtering

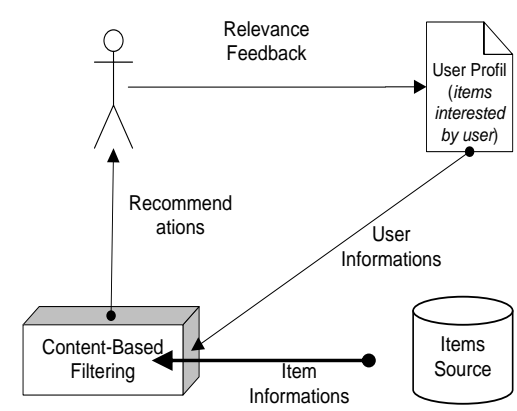

Gambar 2.3. Arsitektur Content-Based Filtering

Sistem berbasis pengetahuan menggunakan struktur pengetahuan untuk membuat kesimpulan tentang kebutuhan pengguna dan preferensi-nya. Sebuah sistem berbasis pengetahuan yang penting adalah teknik yang dimanfaatkan dalam sistem rekomendasi yaitu penalaran berbasis kasus (case based reasoning), merupakan teknik prediksi yang mengambil yang serupa (sebelumnya yang tersimpan) sesi rekomendasi, atau produk, dari kasus dasar dan menggunakan kembali informasi yang tersimpan dalam kasus ini dalam rangka untuk mengidentifikasi set produk yang direkomendasikan.

Sistem Rekomendasi metode hybrid yaitu menggabungkan dua atau lebih teknik dalam rangka untuk mendapatkan kinerja yang lebih baik dengan keterbatasan yang lebih sedikit dari masing-masing pendekatan Metode hybrid (gabungan) [5] antara dua atau lebih teknik penyaringan informasi digunakan untuk meningkatkan kualitas dari keluaran sistem rekomendasi yang diberikan kepada pengguna.

\section{B. Layanan Berbasis Lokasi (LBL)}

LBL adalah informasi layanan yang dapat diakses dengan perangkat mobile melalui jaringan selular dan memanfaatkan kemampuannya tentang informasi lokasi dari perangkat mobile. LBS juga adalah sebuah layanan wireless-IP yang menggunakan informasi geografis untuk melayani pengguna mobile phone. Atau layanan aplikasi apapun yang memanfaatkan posisi terminal mobile [7].

Jadi location-based system adalah kelas umum layanan program komputer yang digunakan untuk memasukkan kontrol khusus untuk data lokasi dan waktu sebagai fitur kontrol dalam program komputer. Dengan demikian LBS adalah sebuah informasi dan memiliki beberapa manfaat dalam Jaringan Sosial hari ini sebagai layanan navigasi, yang dapat diakses dengan perangkat mobile melalui jaringan selular dan yang menggunakan informasi tentang posisi geografis dari perangkat mobile [10]. Pada Gambar 2.4 dibawah ini menunjukkan komponen dasar dari sebuah layanan berbasis lokasi.

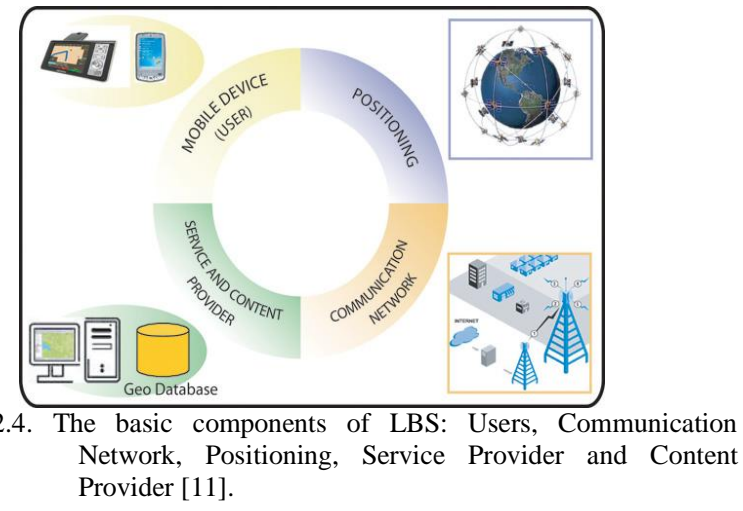

\section{Perancangan dan Analisis Sistem}

\section{A. Perancangan Sistem}

Gambaran tentang sistem rekomendasi yang digunakan dalam penelitian ini diilustrasikan pada Gambar 3.1.

Ilustrasi sistem rekomendasi aplikasi Ternate Island dimulai dari masukan aktifitas user member (anggota) baik secara eksplisit (nilai ratings, data umur pengguna maupun bayaknya komentar spot) dan dari masukan aktifitas pengguna secara implisit (waktu lama kunjungan maupun frekuensi banyaknya kunjungan). Kemudian menjadi masukan ke sistem rekomendasi yang terbagi menjadi dua modul, yaitu pertama modul CF (Collaborative Filtering) yang menyaring spot-spot Ternate Island berdasarkan kemiripan user age dan user rating teman-temannya satu cluster. Kedua yaitu modul LBF (Location Based Sistem) yang menyaring informasi berdasarkan jarak terdekat antara posisi user saat ini dengan jarak pada posisi spot-spot Ternate Island. Keluaran sistem berupa daftar spot-spot hasil penyaringan modul CF dan modul LBF yang merekomendasikan spot sesuai dengan preferensi dan jarak terdekat dari pengguna saat ini.

\section{B. Analisis Kebutuhan Pengguna}

Sistem aplikasi Ternate Island ditujukan kepada calon wisatawan global yang ingin mengetahui informasi kuliner dan wisata di daerah pulau ternate. Pengguna membutuhkan sebuah panduan informasi mengenai kuliner dan wisata Ternate seperti layaknya sebuah booklet yang diharapkan tidak sekedar menawarkan informasi secara pasif tetapi juga lebih aktif dalam hal merekomendasikan spot/tempat wisata 
Rancang Bangun Sistem Rekomendasi Pariwisata Mobile Advertising Menggunakan Metode Hybrid Filtering Sebagai Pemberdayaan Masyarakat Usaha Kecil Menengah (UKM) di Pulau Ternate

dan kuliner di Pulau Ternate secara otomatis dengan berdasarkan preferensi dan kebutuhan pengguna.

Pada tahapan ini dilakukan analisis kebutuhan pengguna dan sistem dalam bentuk use case diagram. Diagram use case menggambarkan runtutan aksi dari aktor dan kemampuan yang dapat dilakukannya dalam sistem. Gambar 3.2. di bawah menjelaskan aktor dan aksinya dalam sistem.

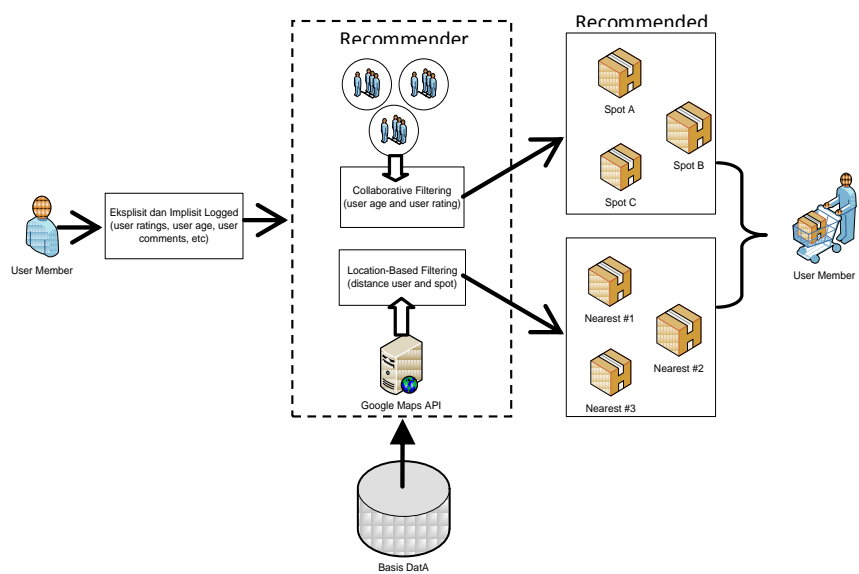

Gambar 3.1. Blog diagram sistem rekomendasi.

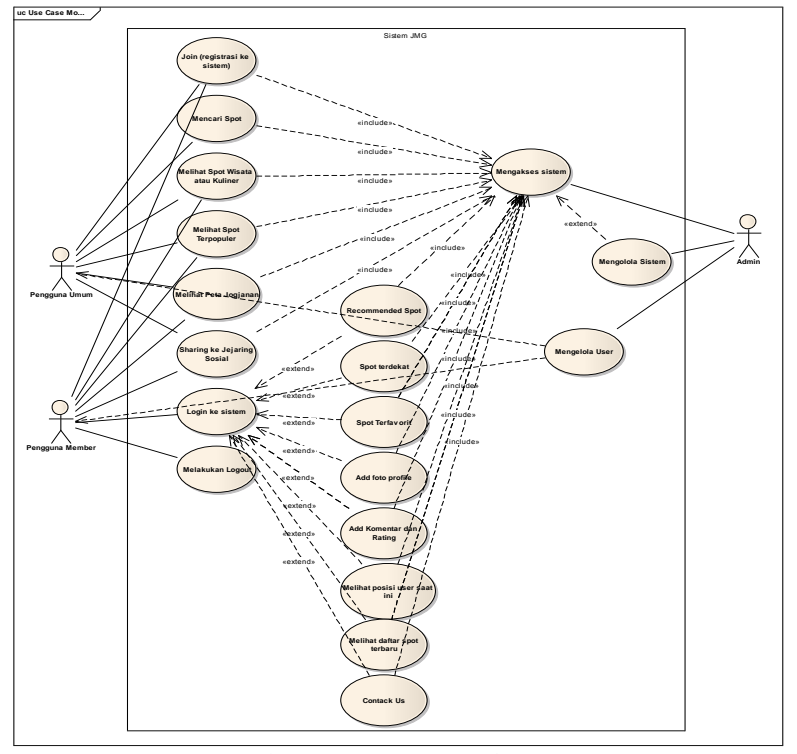

Gambar 3.2. Use-Case Diagram.

\section{Analisis Kebutuhan Sistem}

Aplikasi Ternate Island merupakan aplikasi Mobile Advertising berbasis platforms JQuery Mobile. Aplikasi ini mengkonsumsi data yang sudah tersedia dalam satu sistem yang lebih besar dalam sistem Ternate Island. Arsitektur sistem dapat dilihat pada Gambar 3.3 di bawah ini.

\section{Perancangan Basis Data}

Perancangan database merupakan perancangan sistem basis data yang akan digunakan sesuai kebutuhan sistem. Dalam implementasi sistem Ternate Island kami menggunakan MySQL sebagai sistem basis data yang digunakan. Adapun perancangan database sistem seperti ditunjukkan Gambar 4.4.

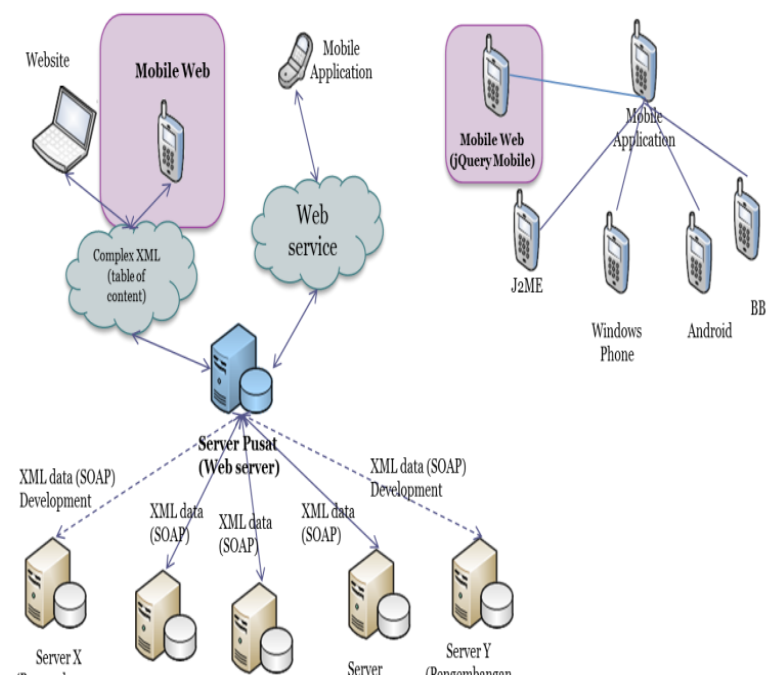

Gambar 3.3. Arsitektur Sistem Ternate Island.

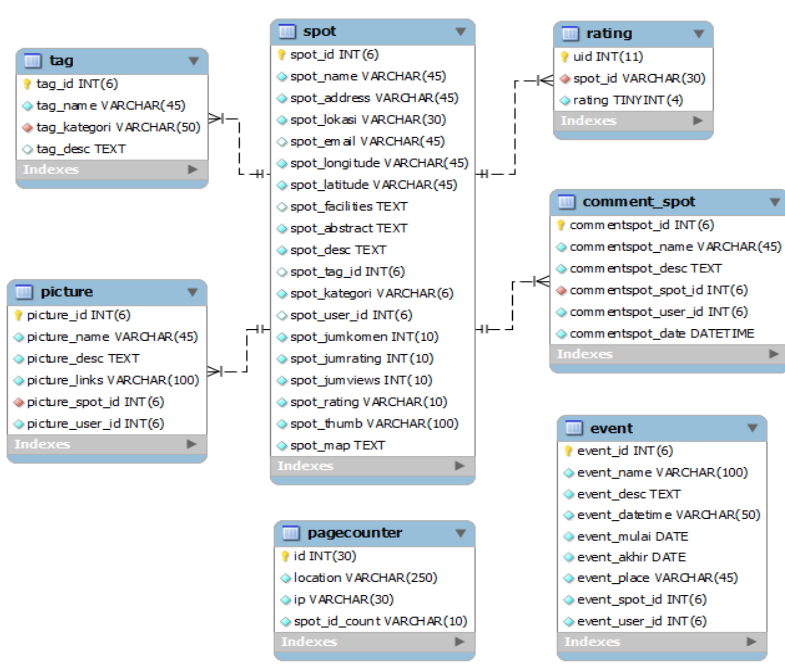

Gambar 3.4. Perancangan Basis Data Sistem.

\section{E. Perancangan Antarmuka}

Antarmuka pada aplikasi Ternate Island menggunakan dukungan browser sebagai halaman aplikasi untuk menampilkan informasi kepada pengguna. Tampilan sketch yang dibuat pada aplikasi wisata dan kuliner aplikasi Ternate Island seperti diperlihatkan pada Gambar 3.5.

\section{IMPLEMENTASI SISTEM}

\section{A. Pengujian Tampilan Menu Utama}

Aplikasi ini merupakan gagasan untuk membuat Layanan Informasi Wisata dan Kuliner pulau Ternate berbasis Teknologi Informasi. Arsitektur yang Layanan Informasi Wisata dan Kuliner tersebut dapat dilihat pada Gambar 4.1. 
Untuk mendapatkan data wisata dan kuliner dari sistem layanan informasi tersebut, aplikasi mobile client haruslah mengakses data web server yang sudah dibuat oleh hosting dengan koneksi via http (online mode). Web server tersebut berupa layanan server yang dibuat dengan menggunakan PHP dan pustaka jQuery Mobile, yang sudah disediakan oleh admin/owner (pengelola) untuk di sebarluaskan secara global dalam dunia maya (internet).

Pengujian aplikasiTernateIsland layanan wisata dan kulin er pulauTernate, Kota Ternate, Maluku Utara untuk pengujian tampilan interface menu utama seperti di tunjukan pada Gambar 4.1.
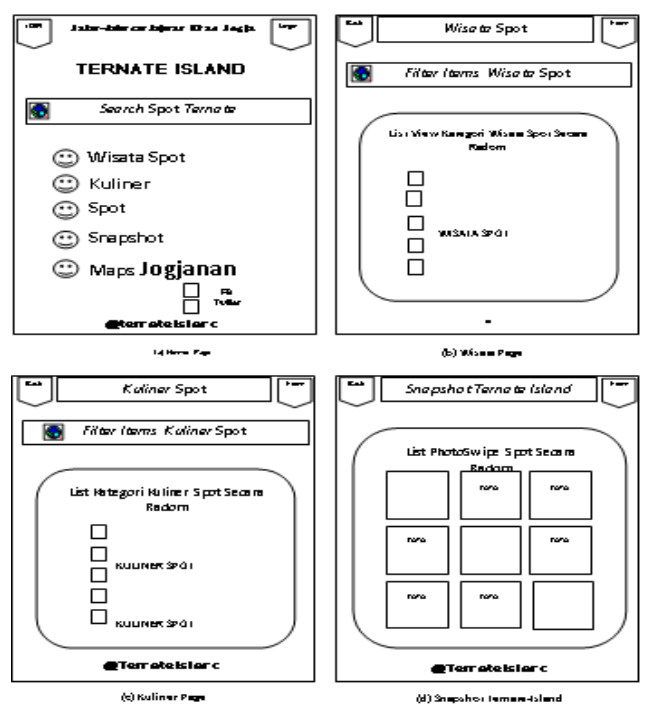

Gambar 3.5. Perancangan Antarmuka

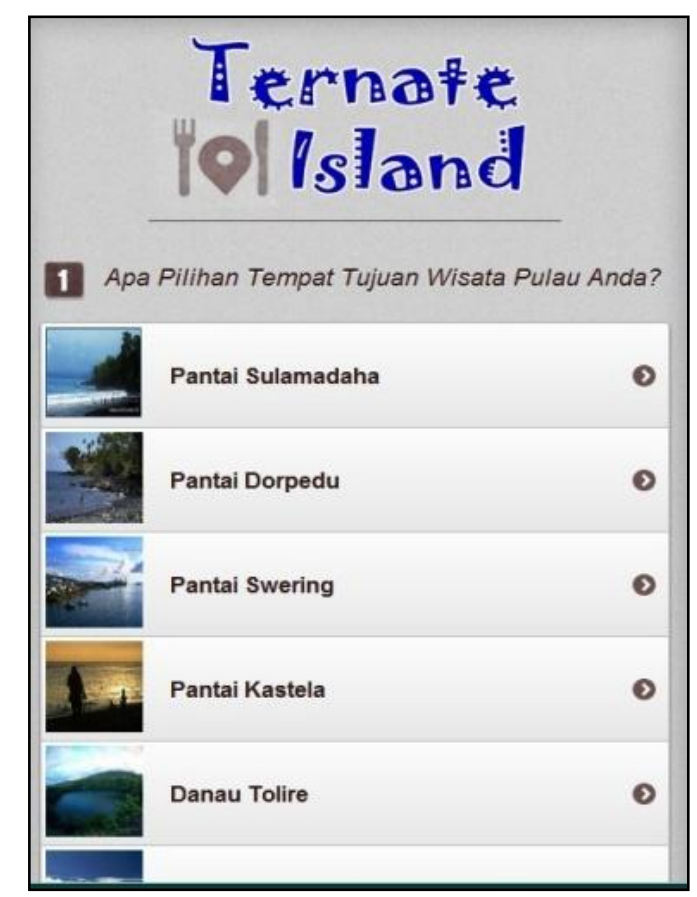

Gambar 4.1. Screen shot Menu Utama Aplikasi Ternate-Island.

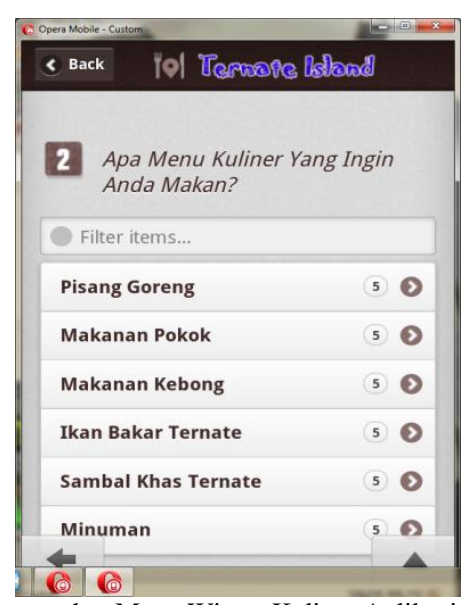

Gambar 4.2. Screen shot Menu Wisata Kuliner Aplikasi Ternate-Island.

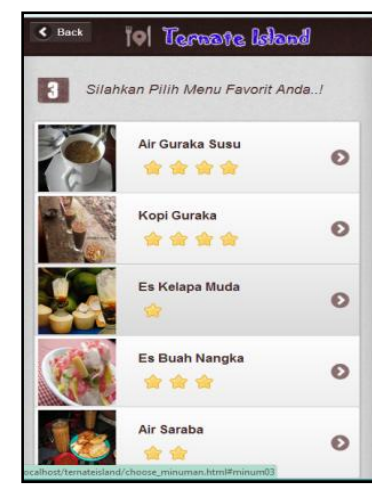

(a) Menu Kuliner Minuman

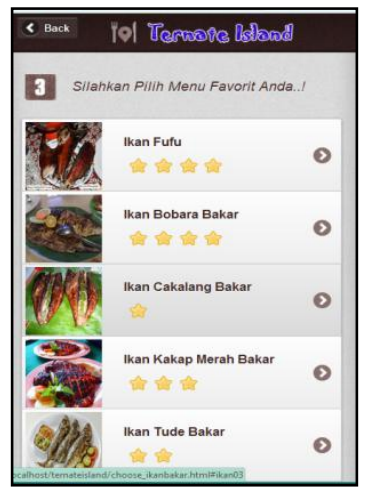

(b) Menu Kuliner Ikan Bakar Gambar 4.3.Pilihan menu kuliner aplikasi Ternate-Island.

\section{B. Pengujian Fitur Peta Virtual Google Maps API}

Layanan peta virtual dengan menggunakan Google Maps API dapat diakses dengan klik icon maps pada halaman detail spot. Halaman icon Maps menunjukkan alamat url ke aplikasi Google Maps yang menunjukkan peta lokasi wisata/kuliner di kota ternate tersebut berada. Selain itu aplikasi juga menampilkan lokasi pengguna berada dengan bantuan GPS. Peta ini dapat diperbesar (zoom in) ataupun diperkecil (zoom out) sesuai keinginan pengguna. Gambar tampilan peta dapat dilihat pada Gambar 4.4. dibawah ini.
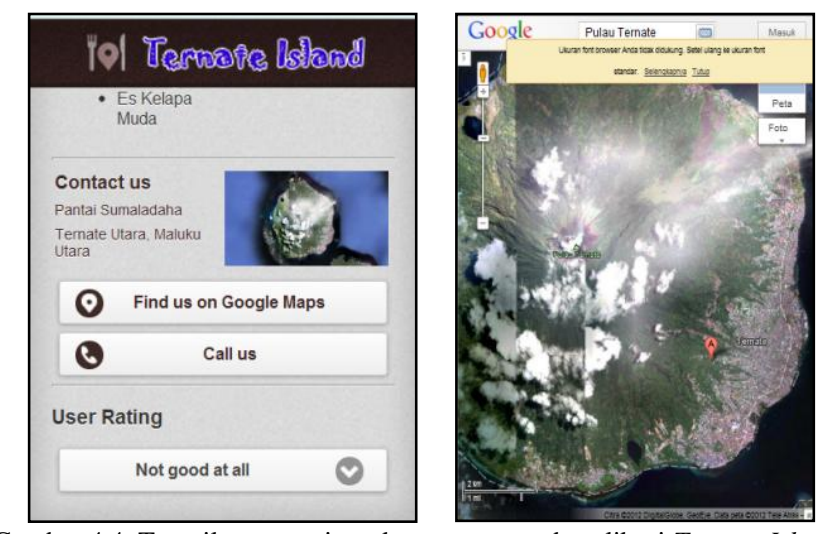

Gambar 4.4. Tampilan peta wisata kota ternate pada aplikasi Ternate-Island. 


\section{KESIMPULAN DAN SARAN}

\section{A. Kesimpulan}

Dari hasil pembahasan sebelumnya, maka dapat ditarik Kesimpulan yang dapat diperoleh dari pembahasanpembahasan pada bab-bab sebelumnya sebagai berikut:

1. Pengembangan antarmuka Mobile Advertising di Kota Ternate ini telah mampu menyediakan akses informasi wisata dan kuliner Pulau Ternate dengan baik melalui uji coba pada mobile emulator dan beberapa tipe browser.

2. Penelitian ini dapat membuat suatu aplikasi yang dapat mengintegrasikan antara peta virtual Google Maps dan layanan informasi kuliner dan wisata di Kota Ternate dengan berbagai fitur antara lain, daftar kuliner dan wisata, melihat detail kuliner atau wisata, pemberian rating, dan pencarian..

\section{B. Saran}

Beberapa saran yang dapat diberikan untuk aplikasi ini agar pengembangan ke depannya dapat lebih baik.

1. Penambahan berbagai macam fitur-fitur khusus yang lebih menunjukkan kemampuan HTML5, misalnya pemanfaatan geolocation dan offline storage untuk teknologi penentuan posisinya.

2. Pada aplikasi ini belum menggunakan algoritma tertentu untuk proses data mining nya sehingga pemanfaatan data pengunjung dapat lebih optimal untuk tujuan e-commerce.

3. Perlu ditambahkan system keanggotaan (membership) agar dapat dicatat banyaknya pengguna dan pengunjung suatu tempat kuliner atau wisata.

\section{DAFTAR PUSTAKA}

[1] Kementerian Budaya dan Pariwisata Republik Indonesia, "Rencana Strategis Kementerian Budaya dan Pariwisata Republik Indonesia Tahun 2010-2014", 2010.

[2] Buhalis D, et al. "eTourism: Informatio Tecnhnology for strategic Tourisn Management”, Prentice Hall, 2003.

[3] Brown B., Chalmers M." Tourism and Mobile Technology", Proceedings of the European Conference on Computer Supported Collacorative Work (CSCW'2003): 2003. 335-355.

[4] Badan Pusat Statistik, (2012, Februari) BPS. [Online]. Available: www.bps.go.id/getfile.php?news=904.

[5] Ricci, F., et al, "Introduction to Recommender System Handbook". Recommender System Handbook, Springer, pp.1-35,2011.

[6] Jannach, D., et al. "Recommender System An Introduction"., Cambridge University Press, 2011.

[7] Ricci, F., "Mobile Recommender System", Faculty of Computer Science. January, 2010.

[8] Deshpande, M.,et al, 'Item-Based Top-N Recommendation Algorithms", ACM Transaction on Information Systems, 2004.

[9] http://ilmukomputer.org/wp-content/uploads/2009/08/amin-website personalization.doc, diakses tanggal 06-06-2012, pukul 10.00 WIB.

[10] Quercia, D.,et al. "Recommending Social Events from Mobile Phone Location Data". IEEE International Conference on Data Mining. pp. 971, 2010.

[11] Shu Wang., et al. "Location Based Services for Mobiles: Technologies and Standards". IEEE International Conference on Communication (ICC), Beijing, China, 2008.

[12] CartouCHe,'Foundations of Location Based Services". Project Cartou CHe - Cartography for Swiss Higher Education. www.ecartouche.ch, 2006.
[13] Stober, Thomas et al. "An Agile Development Approach". Springer, 2010.

[14] Ferdiana, R. "Rekayasa Perangkat Lunak". Bahan Kuliah Rekayasa Perangkat Lunak., JTETI, Universitas Gadjah Mada, 2011. 